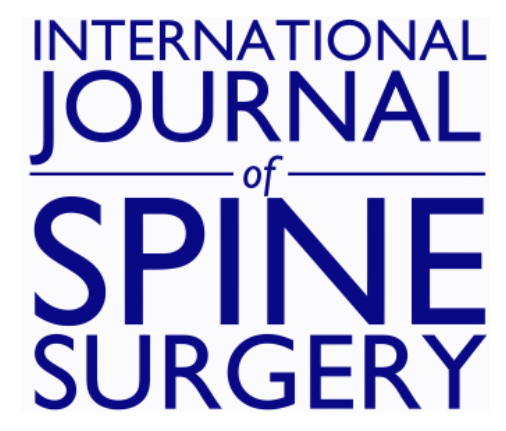

\title{
Impact of a Bundled Payment System on Resource Utilization During Spine Surgery
}

James M. Mok, Maximilian Martinez, Harvey E. Smith, Daniel M. Sciubba, Peter G. Passias, Andrew Schoenfeld, Robert E. Isaacs, Alexander R. Vaccaro, Kris E. Radcliff and Association for Collaborative Spine Research Investigators

Int J Spine Surg 2016, 10 ()

doi: https://doi.org/10.14444/3019

http://ijssurgery.com/content/10/19

This information is current as of April 26, 2023.

Email Alerts Receive free email-alerts when new articles cite this article. Sign up at:

http://ijssurgery.com/alerts

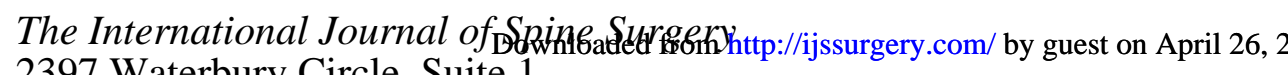
2397 Waterbury Circle, Suite 1,

Aurora, IL 60504, Phone: +1-630-375-1432

(C) 2016 ISASS. All Rights Reserved. 


\section{Impact of a Bundled Payment System on Resource Utilization During Spine Surgery}

James M. Mok, MD, ${ }^{1}$ Maximilian Martinez, MS, ${ }^{2}$ Harvey E. Smith, MD, ${ }^{3}$ Daniel M. Sciubba, MD, ${ }^{4}$ Peter G. Passias, MD, 5 Andrew Schoenfeld, MD, $M S c,{ }^{6}$ Robert E. Isaacs, $M D,{ }^{7}$ Alexander R. Vaccaro, $M D, P h D,{ }^{8}$ Kris E. Radcliff, $M D,{ }^{9}$ Association for Collaborative Spine Research Investigators ${ }_{1}$ Department of Orthopaedic Surgery and Rehabilitation Medicine, University of Chicago, Chicago, IL, 2 Rutgers University - New Jersey Medical School, Newark, NJ, ${ }^{3}$ Department of Orthopaedic Surgery, University of Pennsylvania, Philadelphia, PA, ${ }^{4}$ Department of Neurosurgery, Johns Hopkins University, Baltimore, MD, 5Division of Spinal Surgery, New York University School of Medicine, Westbury, NY, ${ }^{2}$ Department of Orthopedics, Brigham and Women's Hospital, Boston, MA, ${ }^{7}$ Division of Neurosurgery, Duke University, Durham, NC ${ }^{8}$ Department of Orthopaedic Surgery, Thomas Jefferson University, Rothman Institute, Philadelphia, PA, ${ }^{9}$ Department of Orthopaedic Surgery, Thomas Jefferson University, Rothman Institute, Egg Harbor Township, NJ

\section{Abstract}

Background

In a bundled payment system, a single payment covers all costs associated with a single episode of care. Spine surgery may be well suited for bundled payments because of clearly defined episodes of care, but the impact on current practice has not been studied. We sought to examine how a theoretical bundled payment strategy with financial disincentives to resource utilization would impact practice patterns.

Methods

A multiple-choice survey was administered to spine surgeons describing eight clinical scenarios. Respondents were asked about their current practice, and then their practice in a hypothetical bundled payment system. Respondents could choose from multiple types of implants, bone grafts, and other resources utilized at the surgeon's discretion.

Results

Forty-three respondents completed the survey. Within each scenario, 24\%-49\% of respondents changed at least one aspect of management. The proportion of cases performed without implants was unchanged for four scenarios and increased in four by an average of $8 \%$. Use of autologous iliac crest bone graft increased across all scenarios by an average of $18 \%$. Use of neuromonitoring decreased in all scenarios by an average of $21 \%$. Differences in costs were not statistically significant.

\section{Conclusions}

Financial disincentives to resource utilization may result in some changes to surgeons' practices but these appear limited to items with less clear benefits to patients. Choices of implants, which account for the majority of intraoperative costs, did not change meaningfully. A bundling strategy targeting peri-operative costs solely related to surgical practice may not yield substantive savings while rationing potentially beneficial treatments to patient care. Level of Evidence: 5.

KEYWORDS: PATIENT PROTECTION AND AFFORDABLE CARE ACT, SPINE SURGERY, BUNDLED PAYMENTS, HEALTH CARE REFORM, COST, RESOURCE UTILIZATION

VOLUME 10 ARTICLE 19 DOI: 10.14444/3019

\section{Introduction}

The growth of health care spending in the United States has reached a rate and magnitude that is no longer considered sustainable. The high cost of health care, among other issues, directly led to the push for healthcare reform that culminated in the passage of the Patient Protection and Affordable Care Act (PPACA). Among the multiple statutes that make up the law is a provision calling for the design of alternative payment systems to the fee-for-service reimbursement model currently used in the U.S. ${ }^{1,2}$

As mandated by PPACA, the Center for Medicare and Medicaid, a federal agency that administers government insurance programs, currently has introduced four models of bundled payment systems through its Bundled Payment for Care program. ${ }^{3}$ Three represent no significant change from fee-forservice, while the fourth is a prospective model con- 
sisting of bundled payments to hospitals inclusive of physician services. " ${ }^{4}$ Bundled" payment is a single payment that is supposed to cover all costs associated with a single episode of care. A bundled payment system shifts the risk of cost management from payer to provider and theoretically creates shared responsibility for cost control amongst all stakeholders. ${ }^{5}$

Between 2000 and 2010, close to $\$ 290$ billion was spent in the U.S. on fusion-based procedures involving the spine, representing close to 4 million surgical episodes. ${ }^{6}$ Among Medicare beneficiaries (generally Americans age 65 years and over), the cost of care associated with spinal conditions has risen by a factor of 15 over the last decade and now approximates payments related to the management of other chronic diseases such as diabetes. ${ }^{7}$ In addition to considerations of cost, spine surgery may be well-suited for bundled payments because of clearly defined episodes of care and usual related expenses ${ }^{8}$ cervical and lumbar spinal fusions are listed as episodes of care that may be subject to bundled payments by the Centers for Medicare and Medicaid Services. ${ }^{9}$ One of the challenges of bundled payment systems is finding the appropriate balance of financial risk between payers and providers. A potential pitfall is that physicians are financially disincentivized from providing some elective services. The impact of this potential negative conflict of interest has not been studied in spine surgery.

The goal of this study was to determine if a theoretical bundled payment strategy that shifted the financial risk associated with resource utilization to surgeons would result in a change in practice patterns. We examined how this would affect the selection of resources utilized at the surgeon's discretion in eight commonly encountered elective clinical scenarios. The resources examined are a comprehensive representation of the decisions faced by surgeons in the peri-operative period.

\section{Materials and Methods}

A multiple-choice survey (see Appendix) was administered to members of the Association for Collaborative Spine Research, a multi-specialty national academic organization comprising spine surgeons from
North America with an interest in collaborative research using an online survey software and questionnaire tool (Surveymonkey, Palo Alto, CA).

\section{Study population}

Eligible respondents were practicing neurosurgeons or orthopaedic spine surgeons. Respondents were presented with 8 clinical scenarios ( 5 cervical, 3 lumbar) for degenerative spinal conditions for which a decision to perform surgery had already been made (Table 1).

\section{Development of the survey tool}

Key clinical domains, case scenarios, and language were identified in an iterative fashion. The key domains that were thought to change based on negative incentives were instrumentation, bone graft, procedure type, and utilization of ancillary services such as orthotics and intra-operative neurophysiologic monitoring (neuromonitoring). Five common cervical and three common lumbar case vignettes were developed in a manner suggestive of a particular type of operative intervention. Each case differed materially from the other cases in a manner that would reflect complex implant choices in surgical decisionmaking. The scenarios varied by clinical severity, case complexity, and technical difficulty.

\section{Study design}

Within each scenario, respondents were asked to describe their current approach to treatment for the condition described. They were then asked to consider changes to their practice in the setting of a hypothetical bundled payment system. The theoretical bundled payment model was described to respondents as one in which payments allocated to physician compensation were affected by resources utilized at their discretion, such that payment to the physician was reduced proportionately to the cost of the resources. In the model, there was no adjustment made for any difference in patient outcome.

For each scenario, respondents were able to choose from multiple types of surgical implants; bone graft, if applicable; as well as additional services or treatments. In general, fusion-based procedures involving the cervical or lumbar spine require implants and bone graft, whereas uninstrumented fusion utilizes 
bone graft only, and decompression (e.g. laminectomy) does not employ either. The respondents were allowed to choose as few or as many of the options as desired, but were constrained to the multiple options listed. Because the published list price for implants can differ considerably from actual price, the cost for each option was clearly delineated from actual cost data of one urban tertiary care hospital in the northeastern United States. Costs for neuromonitoring were obtained from the same institution using actual charges. Specific cost information is not included here in compliance with hospital policy.

For cervical spine surgery (cases 1-5), treatment options consisted of anterior plate and screws, total disc replacement, combined plate-screw device, lateral mass screws and rods, and no implants (uninstrumented fusion, laminoforaminotomy, or laminectomy). Bone graft options included autologous iliac crest bone graft (harvested from the patient), polyether ether ketone (PEEK) interbody device with morselized graft, structural allograft, tri-cortical allograft, and allograft demineralized bone matrix. Addi- tional treatment choices were comprised of neuromonitoring, intra-operative autologous blood recovery ("cell saver"), hard cervical orthosis, and external bone stimulator (a wearable device to stimulate bone fusion).

For lumbar spine surgery (cases 6-8) treatment options included pedicle screws and rods, cross-link, minimally invasive pedicle screws (higher cost than regular pedicle screws), minimally invasive lateral retractor system, lateral approach interbody fusion device, lateral plate and screws, non-fusion interspinous device, transforaminal lumbar interbody fusion (TLIF) device, and uninstrumented fusion. Bone graft options included autologous iliac crest bone graft, allograft demineralized bone matrix, femoral ring allograft, and recombinant human bone morphogenic protein-2. Additional treatment options entailed neuromonitoring, cell saver, lumbosacral orthosis (LSO), and external bone stimulator.

Table 1. Description of each clinical scenario and the most common combination of procedure, bone graft, and additional treatments chosen by respondents as current practice. (TLIF=transforaminal lumbar interbody fusion).

\begin{tabular}{|c|c|c|}
\hline \multirow{2}{*}{1} & Scenario & C6-C7 disc herniation with monoradiculopathy in a 60 year old non-smoker \\
\hline & Current & Instrumented fusion with anterior plate and screws, structural allograft, neuromonitoring, and hard collar \\
\hline & Scenario & C6-C7 disc herniation with monoradiculopathy in a 50 year old smoker with active worker's compensation claim \\
\hline & Current & Instrumented fusion with anterior plate and screws, structural allograft, neuromonitoring, and hard collar \\
\hline \multirow{2}{*}{3} & Scenario & C5-6, C6-C7 disc herniation with monoradiculopathy in a 60 year old non-smoker \\
\hline & Current & Instrumented fusion with anterior plate and screws, structural allograft, neuromonitoring, and hard collar \\
\hline \multirow{2}{*}{4} & Scenario & C4-C5, C5-C6, C6-C7 disc herniation with monoradiculopathy in a 50 year old smoker with active worker's compensation claim \\
\hline & Current & Instrumented fusion with anterior plate and screws, structural allograft, neuromonitoring, and hard collar \\
\hline \multirow{2}{*}{5} & Scenario & C3-C4, C4-C5, C5-C6, C6-C7 disc herniation with cervical spondylotic myelopathy in a 70 year old \\
\hline & Current & Instrumented fusion with lateral mass screws, iliac crest autograft, allograft demineralized bone matrix, neuromonitoring, and hard collar \\
\hline \multirow{2}{*}{6} & Scenario & L3-L4 isthmic spondylolisthesis with symptomatic radiculopathy in a 50 year old non-smoker \\
\hline & Current & Instrumented fusion with pedicle screws and rods, TLIF device, neuromonitoring; no consensus on bone graft \\
\hline \multirow{2}{*}{7} & Scenario & L4-L5 degenerative spondylolisthesis with neurogenic claudication in a 50 year old non-smoker \\
\hline & Current & Instrumented fusion with pedicle screws and rods, TLIF device, neuromonitoring; no consensus on bone graft \\
\hline \multirow{2}{*}{8} & Scenario & L2-L5 degenerative 40-degree scoliosis with $3 \mathrm{~mm}$ L3-L4 and L4-L5 lateral listhesis and neurogenic claudication in a 50 year old non-smoker \\
\hline & Current & Instrumented fusion with pedicle screws and rods, allograft demineralized bone matrix, neuromonitoring, cell saver \\
\hline
\end{tabular}

Downloaded from http://ijssurgery.com/ by guest on April 26, 2023 
Statistical Methods

Each respondent's choices for current practice and the bundled system for each clinical scenario were examined for differences. Any difference in implant choice for the bundled system was considered a change in procedure, even if the change involved only one of multiple implants chosen as current practice (e.g., current practice of an instrumented posterior lumbar fusion with interbody fusion device would change to an instrumented posterior lumbar fusion without interbody fusion device in the bundled system; this would be considered a change in procedure). Differences in costs between current practice and the bundled system for each scenario were examined for statistical significance using the Student t-test.

In order to better characterize the results of the survey, which allowed many combinations of choices by respondents, the choices were grouped together to allow clinically meaningful data analysis: for "procedure," cases were grouped into those utilizing implants ("instrumented") and those that did not, i.e., uninstrumented fusion and decompression only. For "bone graft," which is necessary for fusion surgery only, cases were grouped into those utilizing autologous iliac crest bone graft and those that used an alternative bone graft such as allograft. Among "additional treatments," proportions of cases utilizing neuromonitoring and a cervical orthosis or LSO were considered. Changes from current practice with the bundled system were measured by comparing the differences in proportions using the Pearson's Chisquare test. If an event maintained a frequency less than five, the Fisher's Exact test was used instead. Statistical significance was set as $\mathrm{p}<0.05$.

\section{Results}

Respondents consisted of 43 spine surgeons surveyed (Table 2). Of the 40 respondents who completed optional demographic information, there were 24 orthopaedic surgeons and 16 neurosurgeons; 35 had completed a fellowship in spinal surgery; 31 reported an academic practice type and 9 private practice. Eight reported 1-5 years of work experience, 9 reported 5-10 years, 10 reported 10-15 years, and 13 reported $>15$ years. Twenty-five were employed by a hospital or health system, 7 were in a private group, 2 were in solo practice, and 1 reported working for an Accountable Care Organization.

For illustrative purposes, the most frequent combination of procedure, bone graft, and additional treatments selected by respondents for each scenario is shown in Table 1. For all 8 scenarios, the hypothetical bundled payment system resulted in changes in management (Table 3, Table 4). Between 24\% and $49 \%$ of respondents stated they would change at least one aspect of their management for a given scenario. Most changes occurred in decisions about bone graft and additional treatments, rather than the procedure (Table 5). Although respondents' choices in bundled systems had lower average total costs than the current practice average total costs, none of the differences for the 8 scenarios were statistically significant.

Comparing the change in choices from current practice for the bundled system, the proportion of uninstrumented cases was unchanged for 4 scenarios and increased for 4 scenarios by an average $8 \%$ (range, $2-10 \%)$; none of these differences were statistically significant (Table 3). In the bundled system, the proportion of respondents choosing autologous iliac crest bone graft increased for all 8 scenarios, while the proportion utilizing neuromonitoring or post-

\begin{tabular}{|c|c|c|}
\hline & $\mathrm{n}$ & $\%$ \\
\hline \multicolumn{3}{|l|}{ Specialty } \\
\hline Orthopaedic Surgery & 24 & $60 \%$ \\
\hline Neurosurgery & 16 & $40 \%$ \\
\hline \multicolumn{3}{|l|}{ Practice type } \\
\hline Academic & 31 & $78 \%$ \\
\hline Private Practice & 9 & $23 \%$ \\
\hline \multicolumn{3}{|l|}{ Work experience } \\
\hline $1-5$ years & 8 & $20 \%$ \\
\hline $5-10$ years & 9 & $23 \%$ \\
\hline $10-15$ years & 10 & $25 \%$ \\
\hline$>15$ years & 13 & $33 \%$ \\
\hline
\end{tabular}


operative hard collar or LSO decreased for all scenarios. Use of autologous iliac crest bone graft increased by an average 18\% (9-24\%) and this difference was statistically significant in 3 scenarios. Use of neuromonitoring decreased by an average 21\% (5-34\%) and this difference was statistically significant in 4 scenarios. Use of hard collar or LSO decreased by an average 9\% (3-21\%), but none of the differences was statistically significant.

\section{Discussion}

Our results support the position that alternative payment schemes can play a role in altering physician behavior. The hypothetical bundled payment system used in this survey, with its clear bias against utilization of peri-operative resources by providing financial disincentives for their use, resulted in changes in some aspect of management in an average of $42 \%$ of respondents within each scenario. The approach utilized in this experiment was simple by design and limited to the impact of financial considerations on perioperative decision-making. Though it does not fully capture the complexity of clinical practice nor currently proposed bundled payment systems (e.g., risk adjustment for patient factors, post-acute care), it could be used as a template for similar initiatives within specialties such as hand surgery, joint replacement, otolaryngology and vascular surgery.

The findings also highlight important limitations inherent to strategies that emphasize surgical costs as the primary means of realizing savings..$^{10}$ Although respondents were provided accurate information regarding the expense of implants used for instrumented fusion surgery, the proportion of procedures cho-

Table 3. Proportion of respondents for each scenario who chose uninstrumented surgery (no implants), autologous iliac crest bone graft (for fusion surgery), neuromonitoring, and hard collar or lumbosacral orthosis (LSO) for fusion surgery. (ICBG=iliac crest bone graft).

\begin{tabular}{|c|c|c|c|c|c|c|c|c|c|c|c|c|}
\hline \multirow[b]{2}{*}{ Case } & \multicolumn{3}{|c|}{ Uninstrumented } & \multicolumn{3}{|r|}{ ICBG } & \multicolumn{3}{|c|}{ Neuromonitoring } & \multicolumn{3}{|r|}{ Brace } \\
\hline & Current & Bundled & $\mathrm{p}$ & Current & Bundled & $\mathrm{p}$ & Current & Bundled & $\mathrm{p}$ & Current & Bundled & $\mathrm{p}$ \\
\hline 1 & $13 \%$ & $23 \%$ & 0.24 & $3 \%$ & $17 \%$ & 0.06 & $63 \%$ & $29 \%$ & 0.002 & $49 \%$ & $28 \%$ & 0.07 \\
\hline 2 & $15 \%$ & $25 \%$ & 0.26 & $20 \%$ & $41 \%$ & 0.07 & $63 \%$ & $32 \%$ & 0.004 & $50 \%$ & $34 \%$ & 0.23 \\
\hline 3 & $3 \%$ & $3 \%$ & 1.0 & $3 \%$ & $20 \%$ & 0.03 & $66 \%$ & $46 \%$ & 0.08 & $50 \%$ & $43 \%$ & 0.50 \\
\hline 4 & $10 \%$ & $10 \%$ & 1.0 & $19 \%$ & $32 \%$ & 0.18 & $61 \%$ & $39 \%$ & 0.05 & $54 \%$ & $51 \%$ & 0.82 \\
\hline 5 & $20 \%$ & $27 \%$ & 0.43 & $27 \%$ & $37 \%$ & 0.42 & $73 \%$ & $68 \%$ & 0.62 & $55 \%$ & $50 \%$ & 0.72 \\
\hline 6 & $0 \%$ & $2 \%$ & 1.0 & $22 \%$ & $41 \%$ & 0.06 & $56 \%$ & $39 \%$ & 0.12 & $29 \%$ & $24 \%$ & 0.62 \\
\hline 7 & $0 \%$ & $0 \%$ & 1.0 & $20 \%$ & $44 \%$ & 0.02 & $61 \%$ & $39 \%$ & 0.05 & $27 \%$ & $20 \%$ & 0.43 \\
\hline 8 & $0 \%$ & $0 \%$ & 1.0 & $27 \%$ & $49 \%$ & 0.04 & $68 \%$ & $54 \%$ & 0.17 & $32 \%$ & $27 \%$ & 0.62 \\
\hline
\end{tabular}

Table 4. Case 7. The highest proportion of respondents changing procedure (22\%) occurred for case 7, but the changes are minor. Two respondents switched from minimally invasive to traditional pedicle screws and rods, and 8 fewer TLIF devices would be used. (TLIF=transforaminal lumbar interbody fusion).

\begin{tabular}{|l|r|r|}
\hline & Current & \\
\hline Pedicle screws and rods & 38 & \\
\hline Minimally invasive pedicle screw system & 30 \\
\hline TLIF device & 1 & 28 \\
\hline Minimally invasive lateral retractor system & \\
\hline Cross link & 1 \\
\hline Uninstrumented & \\
\hline
\end{tabular}


sen without use of implants did not increase enough to reach statistical significance in any scenario. This explains the lack of findings regarding statistically significant changes in costs, as the price of implants represented the largest component of the expense of surgery. The use of implants to decrease the rate of pseudarthrosis after spinal fusion surgery is well established. ${ }^{11,12}$ The results suggest that, despite financial disincentives discouraging the use of implants, the spine surgeons surveyed would continue to utilize them for fusion surgery in order to maximize the likelihood of a successful fusion. It should be noted that there have been multiple initiatives reported that can decrease the cost of implants, ${ }^{13}$ but examining cost variability within the same class of implant is beyond the scope of this paper.

In all scenarios, bundled payments resulted in higher proportion of iliac crest harvest, fewer cases utilizing neuromonitoring, and less brace use. Despite the purported benefits of bone graft substitutes, neuromonitoring, and bracing, the results indicate that respondents can be influenced to change behavior, perhaps because the benefits are perceived as less certain. Autologous iliac crest bone graft harvesting has been associated with donor site morbidity and pain, ${ }^{14}$ which would be eliminated by use of a bone graft substitute. Neuromonitoring allows for constant real-time testing of the patient's neurologic status during surgery, which increases the safety of spine surgery by warning the surgeon of a potential neurologic injury. Cervical and lumbar orthoses provide external immobilization of the spine and may en- hance the likelihood of successful fusion, although the need for external immobilization, particularly in the setting of rigid internal fixation, has been questioned in recent years. ${ }^{15}$ Likewise, some publications have reported the morbidity associated with iliac crest harvest to be minor, ${ }^{16}$ and consequently challenged the need for bone graft substitutes. ${ }^{17}$ Neurologic injury, though potentially devastating, is a rare complication of spine surgery, and therefore routine use of a resource that is usually unnecessary may not be cost-effective. However, our data also demonstrate that bundling may prompt surgeons to riskadjust the need for neuromonitoring based on case complexity. ${ }^{18}$ For example, in case 5, which presented a complex surgery involving the cervical spinal cord, $68 \%$ of respondents would utilize neuromonitoring in the bundled scenario as compared to $73 \%$ who employ neuromonitoring in current practice.

These findings demonstrate the limitations of a strategy that focuses solely on perioperative resource utilization at the expense of other factors that have important roles in determining cost and quality. McCarthy, et al previously analyzed predictors of direct costs of adult spinal deformity surgery. While the type of surgery was a significant contributor, other variables with substantial marginal effects were age and length of stay. ${ }^{19}$ The same authors, using a different cohort of adult spinal deformity patients, found that re-operation dramatically altered the total costs incurred for an individual's surgical care. ${ }^{20}$ The impact of adverse events on costs was further illustrated by Hellsten, et al, who reported that adverse

Table 5. Proportion of respondents who changed treatment choices between current practice and the bundled system. Additional treatments include neuromonitoring, cell saver, hard collar or lumbosacral orthosis, or external bone stimulator.

\begin{tabular}{|c|c|c|c|c|}
\hline Case & Change any aspect & Change procedure & Change bone graft & Change additional treatments \\
\hline 1 & $46 \%$ & $10 \%$ & $22 \%$ & $39 \%$ \\
\hline 2 & $46 \%$ & $12 \%$ & $23 \%$ & $41 \%$ \\
\hline 3 & $37 \%$ & $0 \%$ & $23 \%$ & $22 \%$ \\
\hline 4 & $44 \%$ & $2 \%$ & $16 \%$ & $39 \%$ \\
\hline 5 & $24 \%$ & $7 \%$ & $15 \%$ & $17 \%$ \\
\hline 6 & $44 \%$ & $17 \%$ & $27 \%$ & $20 \%$ \\
\hline 7 & $44 \%$ & $22 \%$ & $27 \%$ & $29 \%$ \\
\hline 8 & $49 \%$ & $12 \%$ & $39 \%$ & $29 \%$ \\
\hline
\end{tabular}

Downloaded from http://ijssurgery.com/ by guest on April 26, 2023 
events occurring in patients undergoing spine surgery over a 4 year period contributed to $\$ 8.4$ million in additional costs, which accounted for $16 \%$ of total direct costs. ${ }^{21}$ Spending on post-acute care has been identified as a main driver in Medicare spending. ${ }^{22}$ Decreasing the frequency and severity of adverse events, preventing re-operation, decreasing length of stay, and judicious utilization of post-acute care all represent opportunities for cost-savings and quality improvement. While the spine surgeon serves an important role in some of these determinations, many are not in their control. It is unlikely that substantive savings can be actualized without a concerted effort on the part of hospitals and payers, as well as a change in attitudes by all stakeholders toward responsible stewardship of healthcare resources.

Strengths of the study include the design of the survey, which contained scenarios, cost information, and treatment choices of high clinical relevance. The treatment options mirrored decision-making that occurs in clinical practice. Limitations include restricting respondents to the options contained in the survey. A survey may also not reflect actual behavior. Clinical outcome was not a consideration. The clinical scenarios were single sentence descriptions that may also not have provided enough information for respondents to choose treatment options. Moreover, the respondents may not accurately reflect the broader spine surgical community, though a range of experience, practice pattern and geographic locations was represented. The impacts of practice pattern and inherent treatment biases of individual surgeons on decision-making are important, but difficult to control for. A larger number of respondents may have detected differences that reach statistical significance. However, considering the length of the survey, administering it to the members of a larger organization would have likely resulted in a low response rate that would create problematic non-response bias. Finally, the study examines only one decision among many available to the surgeon as they consider how best to treat a patient. It does not address possible impacts of decision-making during preoperative and post-operative management and the potential savings to be realized in those areas. However, because implants make up a large proportion of cost, approximately $60 \%$ of the direct costs of fu- sions, ${ }^{20,23}$ we believe this facet of management merits study.

In conclusion, a survey of spine surgeons revealed that financial disincentives to resource utilization would result in limited changes to surgeon choices, with some decreased utilization of items with less clear benefits to patients. Choices related to implants, which account for the majority of intraoperative costs, did not change meaningfully. Though theoretical, a strategy that targets solely the surgeon to decrease perioperative costs and is actualized through changes in surgical practice may not yield substantial savings while resulting in the rationing of potentially beneficial treatments. The promise of bundled payments lies in aligning interests and sharing responsibility among physician, hospital, and payer to create change in the form of clinical pathways, efficiency, quality care, identification of high-risk patients, and standardization when appropriate. An effective strategy should emphasize patient outcomes and use a balanced approach to incentivize all stakeholders to accomplish the dual goals of decreased cost and improved quality.

\section{References}

1. Manchikanti L, Caraway DL, Parr AT, Fellows B, Hirsch JA. Patient Protection and Affordable Care Act of 2010: reforming the health care reform for the new decade. Pain physician. Jan-Feb 2011;14(1):E35-67.

2. The Affordable Care Act: Lowering Medicare Costs by Improving Care: Centers for Medicare and Medicaid Services; 2012.

3. Friermood TG, McCardel B, Naas PL. Pros and Cons of Bundled Payments Participation. AAOS Now. March 2014, 2014: 17, 22-23.

4. Delisle DR. Big things come in bundled packages: implications of bundled payment systems in health care reimbursement reform. American journal of medical quality : the official journal of the American College of Medical Quality. Jul-Aug 2013;28(4):339-344.

5. Bushnell BD. Developing a Bundled Pricing Strategy. AAOS Now. March 2014, 2014: 16-17. 6. Goz V, Weinreb JH, McCarthy I, Schwab F, 
Lafage V, Errico TJ. Perioperative complications and mortality after spinal fusions: analysis of trends and risk factors. Spine. Oct 15 2013;38(22):1970-1976.

7. Chen E, Tong KB, Laouri M. Surgical treatment patterns among Medicare beneficiaries newly diagnosed with lumbar spinal stenosis. The Spine Journal. Jul 2010;10(7):588-594.

8. Ugiliweneza B, Kong M, Nosova K, et al. Spinal surgery: variations in health care costs and implications for episode-based bundled payments. Spine. Jul 1 2014;39(15):1235- 1242.

9. Bundled Payments for Care Improvement (BPCI) Initiative: General Information.

http://innovation.cms.gov/initiatives/bundled-

payments/. Accessed 10/16, 2015.

10. Okike K, O'Toole RV, Pollak AN, et al. Survey finds few orthopedic surgeons know the costs of the devices they implant. Health Aff (Millwood). Jan 2014;33(1):103-109.

11. Wang JC, McDonough PW, Endow KK, Delamarter RB. Increased fusion rates with cervical plating for two-level anterior cervical discectomy and fusion. Spine. Jan 2000;25(1):41-45.

12. Kornblum MB, Fischgrund JS, Herkowitz HN, Abraham DA, Berkower DL, Ditkoff JS. Degenerative lumbar spondylolisthesis with spinal stenosis: a prospective long-term study comparing fusion and pseudarthrosis. Spine. Apr 1 2004;29(7):726-733; discussion 733-724.

13. Eiferman D, Bhakta A, Khan S. Implementation of a shared-savings program for surgical supplies decreases inventory cost. Surgery. Oct 2015;158(4):996-1002.

14. Arrington ED, Smith WJ, Chambers HG, Bucknell AL, Davino NA. Complications of iliac crest bone graft harvesting. Clinical orthopaedics and related research. Aug 1996(329):300-309.

15. Bible JE, Biswas D, Whang PG, Simpson AK, Rechtine GR, Grauer JN. Postoperative bracing after spine surgery for degenerative conditions: a questionnaire study. The spine journal : official journal of the North American Spine Society. Apr 2009;9(4):309-316.

16. Loeffler BJ, Kellam JF, Sims SH, Bosse MJ. Prospective observational study of donorsite morbidity following anterior iliac crest bone-grafting in orthopaedic trauma reconstruction patients. The Jour- nal of bone and joint surgery. American volume. Sep 19 2012;94(18):1649-1654.

17. Radcliff K, Hwang R, Hilibrand A, et al. The effect of iliac crest autograft on the outcome of fusion in the setting of degenerative spondylolisthesis: a subgroup analysis of the Spine Patient Outcomes Research Trial (SPORT). The Journal of bone and joint surgery. American volume. Sep 19

2012;94(18):1685-1692.

18. Lall RR, Hauptman JS, Munoz C, et al. Intraoperative neurophysiological monitoring in spine surgery: indications, efficacy, and role of the preoperative checklist. Neurosurgical focus. Nov

2012;33(5):E10.

19. McCarthy IM, Hostin RA, O'Brien MF, et al. Analysis of the direct cost of surgery for four diagnostic categories of adult spinal deformity. The spine journal : official journal of the North American Spine Society. Dec 2013;13(12):1843-1848.

20. McCarthy I, Hostin R, Ames C, et al. Total Hospital Costs of Surgical Treatment for Adult Spinal Deformity: An Extended Follow-up Study. The spine journal : official journal of the North American Spine Society. Jan 242014.

21. Hellsten EK, Hanbidge MA, Manos AN, et al. An economic evaluation of perioperative adverse events associated with spinal surgery. The spine journal : official journal of the North American Spine Society. Jan 2013;13(1):44-53.

22. Chandra A, Dalton MA, Holmes J. Large increases in spending on postacute care in Medicare point to the potential for cost savings in these settings. Health Aff (Millwood). May

2013;32(5):864-872.

23. Singh K, Nandyala SV, Marquez-Lara A, et al. A perioperative cost analysis comparing single-level minimally invasive and open transforaminal lumbar interbody fusion. The spine journal: official journal of the North American Spine Society. Aug 1 2014;14(8):1694-1701.

\section{Disclosures \& COI}

Isaacs has consultancy, grants, and royalties with $\mathrm{Nu}-$ vasive; is director of and has an ownership interest in SafeRay Spine, LLC; has an ownership interest in SafeWire, LLC, has an ownership interest in VilaSpine LTD; has an ownership interest in Vertera 
Spine; has received travel reimbursement from the Association for Collaborative Spine Research; and is scientific advisor to and has ownership interest in Providence Medical Technology. Martinez reports no conflicts of interest. Mok is a consultant for Stryker Spine. Passias is an unpaid consultant for Medicrea and reports no other conflicts of interest. Radcliff owns stock in and is an unpaid consultant for 4WEB Medical; a Board member of the ACSR; paid consultant to Altus Spine; paid consultant and recipient of research support from DePuy; paid consultant, recipient of research support and IP royalties from Globus Medical; unpaid consultant for LDR; paid consultant and recipient of research support from Medtronic; has received other support from Medtronic; other support from NEXXT Spine; other support from Nuvasive; paid consultant to Orthopedic Sciences, Inc.; recipient of research support from Pacira Pharmaceuticals Inc., recipient of research support from Paradigm Spine; and other suport from Stryker. Schoenfeld is a recipient of a grant from the Robert Wood Johnson Foundation, which was paid to his institution. Sciubba has consulted for Medtronic and has received honoraria from DepuySynthes and Orthofix. Smith has received honoraria from DePuy Spine. Vaccaro reports other from Replication Medica, personal fees from DePuy, personal fees from Medtronics, personal fees from Stryker Spine, personal fees and other from Globus, other from Paradigm Spine, personal fees and other from Stout Medical, other from Progressive Spinal Technologies, other from Advanced Spinal Intellectual Properties, personal fees from Aesculap, other from Spine Medica, other from Computational Bio- dynamics, other from Spinology, other from In Vivo, other from Flagship Surgical, other from Cytonics, other from Bonovo Orthopaedics, other from Electrocore, other from Gamma Spine, other from Location Based Intelligence, other from FlowPharma, other from R.S.I., personal fees from Gerson Lehrman Group, from Guidepoint Global, personal fees from Medacorp, other from Rothman Institute and Related Properties, other from AO Spine, personal fees and other from Innovative Surgical Design, other from Association of Collaborative Spine Research, personal fees from Orthobullets, personal fees from Thieme, personal fees from Jaypee, personal fees from Elsevier, personal fees from Taylor Francis/Hodder and Stoughton, personal fees from Expert Testimony, personal fees from Ellipse, personal fees from Vertex, personal fees from Avaz Surgical, other from Clinical Spine Surgery, outside the submitted work.

\section{Corresponding Author}

James M. Mok, M.D., Department of Orthopaedic Surgery and Rehabilitation Medicine, University of Chicago, 5841 S. Maryland Ave MC3079, Chicago, IL 60637.jmok@bsd.uchicago.edu.

Published 16 May 2016.

This manuscript is generously published free of charge by ISASS, the International Society for the Advancement of Spine Surgery. Copyright @ 2016 ISASS. To see more or order reprints or permissions, see http://ijssurgery.com. 